\title{
Influência do pré-condicionamento ácido em dentina na resistência de união imediata de sistemas adesivos autocondicionantes de dois passos
} Influence of previous acid etching of dentin at the bond strength of two-steps self-etch adhesives

Vicente Castelo Branco Leitune ${ }^{1}$, Fabrício Mezzomo Collares', Marília Paulus², Carolina Rocha Augusto², Susana Maria Werner Samuel ${ }^{3}$

\begin{abstract}
Objective: To evaluate the influence of prior acid-etching to the microshear bond strength of two commercial two-step self-etching adhesive system. Methods: Thirty-two bovine lower incisive were divided into four groups. ClearFill SE Bond and AdheSE were used. Prior acid etching was applied in the half of the teeth. On the other half of the adhesive system were applied according manufacturer. Six cylindrical restorations were produced in each tooth, with adhesive area of $0.88( \pm 0.03) \mathrm{mm}^{2}$. After 24 hours of restoration procedure, the restoration was submitted to a microshear bond strength test with a cross-head speed of $1 \mathrm{~mm} / \mathrm{min}$. Data were analyzed with one-way ANOVA (adhesive system and prior acid etching), with $5 \%$ of statistical significance level. Results: The average bond strength values of all groups ranged from 16,25 to $21,71 \mathrm{MPa}$. However, no statistical difference were detected among all groups, regardless of clinical procedure $(p>0.05)$. Conclusion: The prior acid etching of the dentin did not affect the immediate bond strength of the two commercial two-step self-etching adhesive system.
\end{abstract}

Keywords: Dentin, Dentin-bonding agents, Acid etching.

\section{Resumo}

Objetivo: Avaliar a influência do pré-condicionamento da dentina com ácido fosfórico sobre a resistência de união de dois sistemas adesivos autocondicionantes de dois passos. Métodos: Foram utilizados 32 incisivos bovinos, divididos aleatoriamente em 4 grupos. Os grupos receberam a aplicação dos sistemas adesivos autocondicionantes ClearFil SE Bond $\left(G_{C L}\right)$ ou AdheSE $\left(G_{A D}\right)$. Dois grupos, $G_{A D p a}$ e $G_{C L p a}$, receberam, antes da aplicação do primer, o condicionamento com ácido fosfórico. Em cada dente foram confeccionados seis restaurações cilíndricas com área adesiva de $0,88( \pm 0,03) \mathrm{mm}^{2}$. Após 24 horas, os dentes foram submetidos ao ensaio de microcisalhamento, em uma máquina de ensaios universal, com velocidade de $1 \mathrm{~mm} / \mathrm{min}$. A análise dos dados foi realizada com ANOVA de uma via, com nível de significância de 5\%. Resultados: Os valores médios de resistência de união variaram entre 16,25 e $21,71 \mathrm{MPa}$, entretanto não houve diferença estatisticamente significativa entre todos os grupos avaliados $(p>0,05)$. Conclusão: $O$ condicionamento ácido da dentina não influenciou a resistência de união imediata dos dois sistemas adesivos autocondicionantes de dois passos.

Descritores: Dentina. Adesivos. Ataque ácido dentinário.
${ }^{1}$ Professor Adjunto do Departamento de Odontologia Conservadora, Universidade
Federal do Rio Grande do Sul, Faculdade de Odontologia, Laboratório de Materiais Dentários. Porto Alegre, RS, Brasil.

${ }^{2}$ Aluna do Programa de Pós - Graduação em Odontologia, Universidade Federal do Rio Grande do Sul, Faculdade de Odontologia, Laboratório de Materiais Dentários. Porto Alegre, RS, Brasil.

${ }^{3}$ Professora Titular do Departamento de Odontologia Conservadora, Universidade Federal do Rio Grande do Sul, Faculdade de Odontologia, Laboratório de Materiais Dentários. Rua Ramiro Barcelos, 2492, Rio Branco, 90035-003, Porto Alegre, RS, Brasil.

Correspondência: Vicente Castelo Branco Leitune, (51) 3308-5198. E-mail vicente.leitune@ufrgs.br.

\section{Introdução}

O insucesso das restaurações diretas pode ser ocasionado pela perda de retenção e adaptação marginal (KIM et al., 2013). Com o objetivo de aumentar a retenção e manter a adaptação marginal das restaurações, lança-se mão de sistemas adesivos. Os sistemas adesivos classificam-se como convencionais e autocondicionantes (VAN MERRBEEK et al., 2011; PASHLEY et al., 2011). Os convencionais requerem a aplicação de ácido fosfórico, lavagem e secagem da estrutura dental. Esses passos clínicos aumentam a sensibilidade técnica do procedimento restaurador (BEER et al., 2012). O aumento da sensibilidade técnica pode estar associado à redução da durabilidade das restaurações (VAN MEERBEEK et al., 2011).

Os sistemas adesivos autocondicionantes penetram no substrato dentário simultaneamente à desmineralização. Embora essa desmineralização pareça ser suficiente no tecido dentinário, ainda se apresenta deficiente no esmalte (MULLER et al., 1998). A eficácia da desmineralização do primer dos sistemas autocondicionantes é inferior ao ácido fosfórico utilizado nos sistemas adesivos convencionais (WATANABE et al., 1993). Os sistemas adesivos autocondicionantes de dois passos caracterizam-se por serem menos ácidos que os sistemas autocondicionantes de um passo e podem não ser suficientemente ácidos para produzir interfaces adesivas semelhantes às produzidas pelos sistemas convencionais em esmalte (TAY et al., 2001). Devido à dificuldade de desmineralização do esmalte, restaurações realizadas com sistemas adesivos autocondicionantes apresentam maior chance de alteração de cor marginal ao longo do tempo (SCHULDT et al., 2016).

Com o intuito de melhorar a adesão dos sistemas autocondicionantes ao esmalte, tem sido proposto o condicionamento prévio do esmalte com ácido fosfórico (MIYAZAKI et al., 1999; LIMA et al., 2012). Considerando que a aplicação do ácido fosfórico apenas em esmalte é de difícil controle para o clínico, pouco se sabe sobre o efeito do condicionamento ácido prévio na resistência de união de um sistema adesivo autocondicionante à dentina.

Sendo assim, o objetivo do presente estudo foi avaliar a influência do pré-condicionamento da dentina com ácido fosfórico 
sobre a resistência de união de dois sistemas adesivos autocondicionantes de dois passos.

\section{Materiais e Métodos}

\section{Preparação dos espécimes}

Trinta e dois incisivos inferiores bovinos foram selecionados para este estudo e armazenados em água destilada a $4^{\circ} \mathrm{C}$ por até três meses. Os dentes foram embutidos em resina acrílica e a superfície vestibular foi desgastada até exposição superficial da dentina superficial. Para a produção de smear layer padronizada, a superfície dentinária foi polida com lixa de granulação 600 sob irrigação constante durante 30 segundos.

\section{Procedimentos adesivos}

Os dentes foram aleatoriamente divididos em quatro grupos de acordo com o tratamento dentinário recebido $(n=8)$. A composição química dos sistemas adesivos utilizados neste estudo está descriminada na Tabela 1. Dois grupos receberam a aplicação de sistemas adesivos autocondicionantes, ClearFil SE Bond (Kuraka yOkayama, Japão) e AdheSE (Ivoclar Vivadent, Schaan, Liechtenstein), de acordo com as recomendações dos fabricantes após a produção da smear layer. Para o sistema adesivo AdheSE $\left(G_{A D}\right)$, o primer foi aplicado por 30 segundos e o solvente evaporado por 20 segundos com aplicação de jato de ar. O adesivo aplicado foi fotoativado por 10 segundos. Para o sistema adesivo ClearFil SE Bond $\left(G_{C L}\right)$, o primer foi aplicado por 20 segundo e o solvente evaporado por 20 segundos com jato de ar. $\mathrm{O}$ adesivo foi fotoativado por 10 segundos. Os grupos $\mathrm{G}_{\mathrm{ADpa}}$ e $\mathrm{G}_{\mathrm{CLpa}}$ receberam, antes da aplicação do primer, o tratamento de superfície com aplicação de ácido fosfórico a $37 \%$ por 10 segundos, lavagem com jato de água pelo mesmo tempo, remoção do excesso de água com papel absorvente e aplicação do sistema adesivo conforme as recomendações dos fabricantes. Em cada dente foram confeccionados seis restaurações cilíndricas com área adesiva de $0,88( \pm 0,03) \mathrm{mm}^{2}$ com resina composta Tetric (Ivoclar Vivadent AG, Schaan, Liechtenstein) fotoativada por 30 segundos cada. A fotoativação dos sistemas adesivos e resina composta foram realizadas utilizando um diodo emissor de luz (Radii, SDI, Victoria, Australia). A irradiância de $1200 \mathrm{~mW} / \mathrm{cm}^{2}$ da unidade fotoativadora foi confirmada através do espectrofotômetro digital (OphirOptronics, Danvers, MA, EUA). Os dentes foram armazenados por 24 horas em água destilada em estufa a $37^{\circ} \mathrm{C}$ antes da realização do teste.

\section{Ensaio de microcisalhamento}

A resistência de união foi avaliada através do ensaio de microcisalhamento. Os espécimes foram posicionados numa máquina de ensaio universal (DL-2000, EMIC, PR, Brasil) e a força foi aplicada a uma velocidade de carregamento de $1,0 \mathrm{~mm} / \mathrm{min}$ utilizando um fio de aço $(\varnothing 0,4 \mathrm{~mm})$. O fio de aço foi posicionado na linha de união e tracionado. A resistência de união foi expressa em $\mathrm{MPa}$, considerando o dente como unidade avaliada. Os valores de força foram registrados em Newtons $(\mathrm{N})$ e transformados em megapascal (MPa) pela fórmula: $\mathrm{RU}=$ Força $(\mathrm{N})$ / área adesiva $\left(\mathrm{mm}^{2}\right)$. As médias e desvio padrão da resistência de união dos grupos foram analisados por ANOVA de uma via, com nível de significância de 5\%.
Tabela 1. Composição, $\mathrm{pH}$, e fabricantes dos sistemas adesivos utilizados no estudo.

\begin{tabular}{|c|c|c|c|}
\hline Sistema adesivo & Composição & $\mathrm{pH}$ & Fabricante \\
\hline \multirow[t]{2}{*}{ ClearFil SE Bond } & $\begin{array}{l}\text { Primer: Água, MDP, } \\
\text { HEMA, dimetacrilatos } \\
\text { hidrofílicos, } \\
\text { canforoquinona }\end{array}$ & 2,0 & $\begin{array}{l}\text { Kuraray } \\
\text { Medical } \\
\text { Inc., } \\
\text { Kurashiki, } \\
\text { Okayama, } \\
\text { Japão }\end{array}$ \\
\hline & $\begin{array}{l}\text { Adesivo: MDP, Bis-GMA, } \\
\text { HEMA, canforoquinona, } \\
\text { dimetacrilatos hidrófobos, } \\
\text { adesivo N/N-diethanol p } \\
\text { toluidina, sílica coloidal }\end{array}$ & & \\
\hline \multirow[t]{2}{*}{ AdheSE } & $\begin{array}{l}\text { Primer: Ácido acrilato } \\
\text { fosfórico, Bis-acrilamida, } \\
\text { água, iniciadores e } \\
\text { estabilizadores }\end{array}$ & 1,6 & $\begin{array}{l}\text { Ivoclar } \\
\text { Vivadent } \\
\text { AG, } \\
\text { Schaan, } \\
\text { Liech. }\end{array}$ \\
\hline & $\begin{array}{l}\text { Adesivo: Dimetacrilato, } \\
\text { HEMA, dióxido de sílica } \\
\text { dispersa, iniciadores e } \\
\text { estabilizadores }\end{array}$ & 1.7 & \\
\hline $\begin{array}{l}\text { Condicionamento } \\
\text { ácido }\end{array}$ & Ácido fosfórico 37\% & 0,6 & $\begin{array}{l}\text { FGM, } \\
\text { Joivilie, SC, } \\
\text { Brasil }\end{array}$ \\
\hline
\end{tabular}

\section{Aspectos éticos}

Foram utilizados dentes bovinos provenientes de animais abatidos para fins comerciais da carne. Nenhum procedimento foi realizado nos animais, apenas nos dentes que seriam descartados, após o abate dos animais, considerados material biológico descartável.

\section{Resultados}

Os resultados da análise de resistência de união estão apresentados na Figura 1 e Tabela 2. O grupo $\mathrm{G}_{\mathrm{AD}}$ (sistema adesivo AdheSE aplicado conforme as recomendações do fabricante) apresentou uma média e desvio padrão de 16,25 ( \pm 7,82) MPa. Para o grupo $\mathrm{G}_{\mathrm{CL}}$ (sistema adesivo ClearFil SE Bond aplicado conforme as recomendações do fabricante), a média e desvio padrão foi de 21,71 $( \pm 6,64) \mathrm{MPa}$. Os grupos com o acréscimo da etapa de aplicação do condicionamento ácido prévio a aplicação dos sistemas adesivos $\left(G_{A D p a}\right.$ e $\left.G_{C L p a}\right)$ tiveram média e desvio padrão de 20,02 $( \pm 3,89) \mathrm{MPa}$ e 21,19 ( $\pm 4,17) \mathrm{MPa}$, respectivamente. Não houve diferença estatisticamente significativa entre todos os grupos avaliados $(p>0,05)$.

Tabela 2. Média e desvio padrão da resistência de união, em MPa.

\begin{tabular}{ll}
\hline Grupo experimental & Média ( \pm desvio padrão) \\
\hline $\mathrm{G}_{\mathrm{AD}}$ & $16,25( \pm 7,82)^{\mathrm{A}}$ \\
$\mathrm{G}_{\mathrm{CL}}$ & $21,71( \pm 6,64)^{\mathrm{A}}$ \\
$\mathrm{G}_{\mathrm{ADpa}}$ & $20,02( \pm 3,89)^{\mathrm{A}}$ \\
$\mathrm{G}_{\mathrm{CLpa}}$ & $21,19( \pm 4,17)^{\mathrm{A}}$ \\
\hline Letras iguais na coluna significam que não houve diferença \\
estatisticamente significante (p>0,05).
\end{tabular}




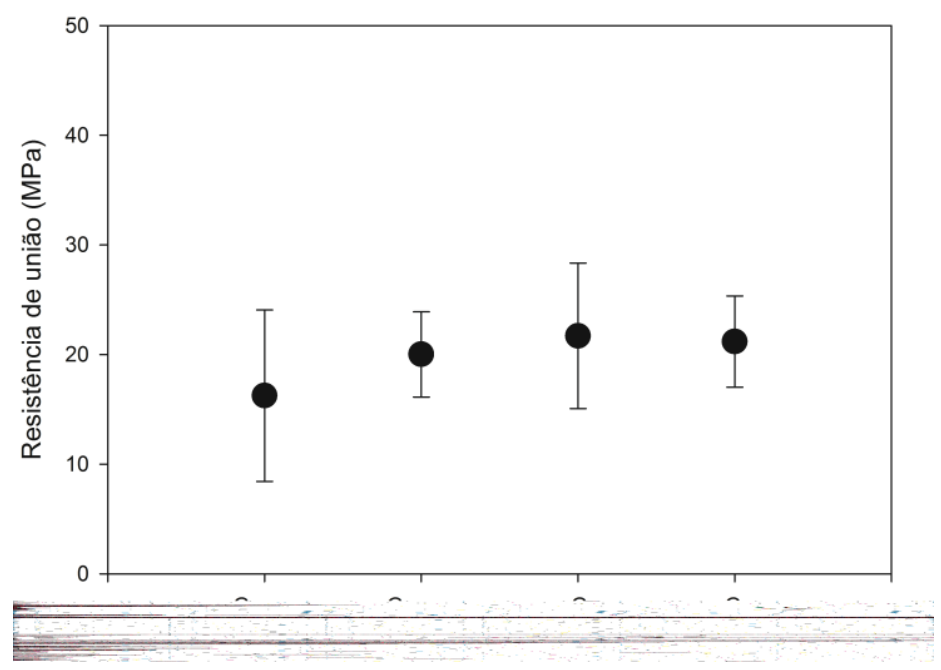

\section{Discussão}

Os sistemas adesivos autocondicionantes de dois passos apresentam resultados laboratoriais e clínicos comparáveis aos sistemas convencionais de três passos (VAN MERRBEEK et al., 2011; PEUMANS et al., 2010). Estes sistemas adesivos, compostos por monômeros ácidos, têm a capacidade de modificar a smear layer (LOHBAUER et al., 2008) promovendo uma resistência mecânica semelhante aos sistemas adesivos convencionais de três passos (OSTBY et al., 2007), promovendo a redução da sensibilidade da técnica de aplicação e praticidade de uso (INOUE et al., 2005). Entretanto a capacidade de desmineralização do esmalte desses sistemas adesivos autocondicionantes é limitada e, com o intuito de aumentar essa desmineralização, possibilitando um maior embricamento micromecânico, o condicionamento ácido prévio do esmalte tem sido proposto (VAN LANDUYT et al., 2006). Apesar do ácido fosfórico utilizado para o condicionamento estar disponível no mercado em forma de gel, o controle da aplicação somente em esmalte é crítico. No presente estudo o ácido fosfórico aplicado previamente ao sistema adesivo autocondicionante de dois passos na dentina não influenciou a resistência de união imediata $(p>0,05)$.

Os adesivos autocondicionantes apresentam a vantagem de desmineralizar e infiltrar a superfície dentária na mesma profundidade, assegurando a completa penetração do adesivo nas zonas desmineralizadas (VAN MEERBEEK et al., 2010). O mecanismo de união ao esmalte e à dentina é baseado em um processo em que os minerais removidos a partir dos tecidos duros dentários são substituídos por monômeros resinosos (VAN MEERBEEK et al., 2003). Esses adesivos autocondicionantes possibilitam um maior controle da umidade dentinária, pois no mesmo momento em que a dentina é desmineralizada, há também a difusão dos monômeros, melhorando o selamento da dentina e diminuindo o risco de sensibilidade. $O$ tempo de aplicação destes adesivos é mais curto e não há a necessidade de lavagem após a sua aplicação além de apresentar menor sensibilidade técnica (DE MUNCK et al., 2005). Os sistemas adesivos autocondicionantes de dois passos podem ser classificados como leve $(\mathrm{pH}>2)$, moderado $(1<\mathrm{pH}<2)$ e forte $(\mathrm{pH}<$ 1), dependo da sua composição (PIVETTA et al., 2008).

De acordo com Van Landuyt (VAN LANDUYT et al., 2005), o tratamento prévio dos tecidos com ácido fosfórico para melhorar a efetividade pode ser indicado, mas deve ser limitado ao esmalte, pois o condicionamento em dentina pode ser considerado extremamente agressivo, levando a exposição das fibras de colágeno, sem que haja o completo preenchimento dos espaços entre as fibrilas de colágeno (VAN MEERBEEK et al., 2010). Entretanto o presente estudo não encontrou diferença entre a aplicação de ácido ou não na dentina na resistência de união imediata. Diversos estudos demonstram 0 aumento da resistência de união do sistema adesivo ao esmalte com o condicionamento ácido prévio à aplicação dos sistemas adesivos (VAN MERRBEEK et al., 2005; WALKER et al., 2000). No esmalte, apesar da acidez dos sistemas adesivos autocondicionantes, a utilização do condicionamento é proposta com o intuito de aumentar a rugosidade superficial, pela desmineralização dos cristais prismáticos e interprismáticos, facilitando a penetração dos monômeros (VAN LANDUYT et al., 2006). Se houver contato do ácido fosfórico à dentina, o tempo de permanência irá expor os túbulos dentinários e as fibras de colágeno, podendo resultar em sensibilidade pósoperatória (LOPES et al., 2002). No esmalte, tanto para os adesivos convencionais quanto para os adesivos autocondicionantes, a adesão do tecido é essencialmente micromecânica. Na dentina, quando se faz o uso dos adesivos convencionais, os mecanismos de adesão são diferentes tendo em vista que o ácido fosfórico é um ácido forte que dissolve o mineral $e$, desta forma as fibras de colágeno ficam expostas após o condicionamento ácido (GEERTS et al., 2012).

O condicionamento ácido fosfórico promove o aumento da permeabilidade e desmineralização do esmalte e da dentina, quando utilizado nos sistemas convencionais. $O$ uso dos adesivos autocondicionantes evita a formação de grandes áreas desmineralizadas (ATOUI et al., 2010). A eficiência do condicionamento ácido e a penetração dos autocondicionantes no esmalte e dentina dependem da capacidade de tamponamento que o substrato oferece e da acidez do material (WATANABE et al., 1993). As zonas de dentina não preenchidas pelo adesivo permitirão que as fibras de colágeno expostas fiquem desprotegidas da ação dos fluidos orais e dentinários, podendo levar a diminuição da resistência de união a longo prazo (PASHLAY et al., 2004; LEITUNE et al., 2010). Sendo assim, apesar de não haver diferença na resistência de união imediata, o condicionamento ácido prévio na dentina deve ser avaliado a longo prazo.

Os sistemas adesivos autocondicionantes estão ganhando cada vez mais espaço na prática clínica. Entretanto ainda apresentam limitações na adesão ao esmalte. Os ensaios clínicos apontam melhora na performance do uso do condicionamento ácido seletivo no esmalte antes do sistema adesivo autocondicionante de dois passos. Apesar de esse condicionamento ser seletivo e limitar-se ao esmalte, o controle do contato do ácido com a dentina é difícil. Entretanto, no presente estudo, o condicionamento ácido da dentina não influenciou a resistência de união imediata de dois sistemas adesivos autocondicionantes.

\section{Conclusão}

O condicionamento ácido prévio em dentina não afeta a resistência de união imediata de sistemas adesivos autocondicionantes de dois passos. 


\section{Referências}

ATOUI, J.A., CHINELATTI, M.A., PALMA -DIBB, R.G., et al. Microleakage in conservative cavities varying the preparation method and surface treatment. J Appl Oral Sci, v.18, n.4, p.421-425, July/Aug. 2010.

BEER, F., BUCHMAIR, A., KORPET, W., et al. Morphology of resindentin interfaces after Er, Cr: YSGG laser and acid etching preparation and application of different bonding systems. Lasers Med Sci, v.27, n.4, p.835-41, July 2012.

DE MUNCK, J., VAN LANDUYT, K., PEUMANS, M., et al. A critical review of the durability of adhesion to tooth tissue: methods and results. J Dent Res, v.84, n.2, p. 118-132, Feb. 2005.

GEERTS, S., BOLETTE, A., SEIDEL, L., et al. An in vitro evaluation of leakage of two etch and rinse and two self-etch adhesives after thermocycling. Int J Dent. 2012; 852841.

INOUE, S., KOSHIRO, K., YOSHIDA, Y., et al. Hydrolytic stability of self-etch adhesives bonded to dentin. J Dent Res, v.84, n.12, p.11601164, Dec. 2005.

KIM, K.L., NAMGUNG, C., CHO, B.H. The effect of clinical performance on the survival estimates of direct restorations. Restor Dent Endod, v.38, n.1, p. 11-20, Feb. 2013.

LEITUNE, V.C., COLLARES, F.M., WERNER SAMUEL, S.M. Influence of chlorhexidine application at longitudinal push-out bond strength of fiber posts. Oral Surg Oral Med Oral Pathol Oral Radiol Endod, v.110, n.5, p. 77-81, Nov. 2010.

LIMA, A.F., DA SILVA, V.B., SOARES, G.P., et al. Influence of previous acid etching on interface morphology and bond strength of self-etching adhesive to cavosurface enamel. Eur J Dent, v.6, n.1, p.56-62, Jan. 2012.

LOHBAUER, U., NIKOLENKO, S.A., PETSCHELT, A., et al. Resin tags do not contribute to dentin adhesion in self-etching adhesives. $\mathbf{J}$ Adhes Dent, v.10, n.2, p.97-103, Feb. 2008.

LOPES, G.C., BARATIERI, L.N., DE ANDRADA, M.A., et al. Dental adhesion: present state of the art and future perspectives.

Quintessence Int, v.33, n.3, p.213-224, Mar. 2002.

MIYAZAKI, M., HIROHATA, N., TAKAGAKI, K., et al. Influence of selfetching primer drying time on enamel bond strength of resin composites. J Dent, v. 27, n.3, p. 203-207, Mar. 1999.

MILLER, R.G., BOWLWS, C.Q., CHAPPELOW, C.C., et al. Application of solubility parameter theory to dentin-bonding systems and adhesive strength correlations. J Biomed Mater Res, v.41, n.2, p. 237-43, Aug. 1998.

OSTBY, A.W., BISHARA, S.E., LAFFOON, J., et al. Influence of selfetchant application time on bracket shear bond strength. Angle Orthod, v.77, n.5, p. 885-889, Sep. 2007.

PASHLEY, D.H., TAY, F.R., YIU, C., et al. Collagen degradation by host-derived enzymes during aging. J Dent Res, v.83, n.3, p. 216221, Mar. 2004
PASHLEY, D.H., TAY, F.R., BRESCHI, L., TJÄDERHANE, L., CARVALHO, R.M., CARRILHO, M., TEZVERGIL-MUTLUAY, A. State of the art etch-and-rinse adhesives. Dent Mater, v. 27, n. 1, p.1-16, Jan. 2011

PEUMANS, M., DE MUNCK, J., VAN LANDUYT, K.L., et al. Eightyear clinical evaluation of a 2-step self-etch adhesive with and without selective enamel etching. Dent Mater, v.26, n.12, p.1176-1184, Dec. 2010.

PIVETTA, M.R., MOURA, S.K., BARROSO, L.P., et al. Bond strength and etching pattern of adhesive systems to enamel: effects of conditioning time and enamel preparation. J Esthet Restor Dent, v. 20, n.5, p.322-335; 2008

SCHULDT, C., BIRLBAUER, S., PITCHIKA, V., CRISPIN, A., HICKEL, R., KÜHNISCH, J. Shear bond strength and microleakage of a self-etching adhesive for fissure sealing after different types of aging. Dent Mater J. v. 35, n. 3, p.490-497, 2016.

TAY, F.R., PASHLEY, D.H. Aggressiveness of contemporary selfetching systems. I: Depth of penetration beyond dentin smear layers. Dent Mater, v.17, n.4, p.296-308, July 2001.

VAN LANDUYT, K.L., DEMUNCK, J., SNAUWAERT, J., et al. Monomer-solvent phase separation in one-step self-etch adhesives. $\mathbf{J}$ Dent Res, v. 84, n. 2, p. 183-188, Feb. 2005.

VAN LANDUYT, K.L., KANUMILLI, P., DEMUNCK, J., et al. Bond strength of a mild self-etch adhesive with and without prior acid etching. J Dent, v. 34, n.1, p.77-85, Jan. 2006.

VAN MEERBEEK, B., DEMUNCK, J., MATTAR, D., et al. Microtensile bond strengths of an etch\&rinse and self-etch adhesive to enamel and dentin as a function of surface treatment. Oper Dent, v.28, n.5, p.647660, Sept./Oct. 2003.

VAN MEERBEEK, B., KANUMILLI, P., DE MUNCK, J., et al. A randomized controlled study evaluating the effectiveness of a two-step self-etch adhesive with and without selective phosphoric-acid etching of enamel. Dent Mater, v.21, n.4, p.375-383, Apr. 2005.

VAN MEERBEEK, B., PEUMANS, M., POITEVIN, A., et al. Relationship between bond-strength tests and clinical outcomes. Dent Mater, v. 26, n. 2, p.100-121, Feb. 2010.

VAN MEERBEEK, B., YOSHIHARA, K., YOSHIDA, Y., et al. State of the art of self-etch adhesives. Dent Mater, v. 27, n.1, p.17-28, Jan. 2011.

WALKER, M.P., WANG, Y., SWAFFORD, J., et al. Influence of additional acid etch treatment on resin cement dentin infiltration. $\mathbf{J}$ Prosthodont, v.9, n.2, p. 77-81, June 2000.

WATANABE I., NAKABAYASHI. N. Bonding durability of photocured phenyl-P in TEGDMA to smear layer-retained bovine dentin. Quintessence Int, v.24, n.5, p.335-342, May 1993. 